\title{
Chronic Nitric Oxide Inhibition In Utero Produces Persistent Pulmonary Hypertension in Newborn Lambs
}

\author{
Jeffrey R. Fineman, ${ }^{\star}$ Jackson Wong, ${ }^{\star}$ Frederick C. Morin III, ${ }^{\star}$ Linda M. Wild, and Scott J. Soifer* \\ *Department of Pediatrics and the Cardiovascular Research Institute, University of California San Francisco, \\ San Francisco, California 94143-0106; and Departments of ${ }^{\ddagger}$ Pediatrics, ${ }^{\ddagger}$ Physiology, and ${ }^{\S}$ Pathology, \\ State University of New York at Buffalo, Buffalo, New York 14214
}

\begin{abstract}
Persistent pulmonary hypertension of the newborn (PPHN) is associated with chronic intrauterine events. Acute nitric oxide (NO) inhibition attenuates the normal increase in pulmonary blood flow at birth. We investigated whether chronic NO inhibition in utero causes persistent pulmonary hypertension. 11 fetal lambs received either a continuous infusion of $N^{\omega}$-nitro-L-arginine (an NO synthesis inhibitor) or $0.9 \%$ saline. Before infusion, acetylcholine (dependent upon endogenous NO production) and sodium nitroprusside (which releases its own NO) produced potent pulmonary vasodilation. After $10.5 \pm 1.5 \mathrm{~d}$ of infusion, acetylcholine did not produce pulmonary vasodilation in $N^{\omega}$-nitro-L-arginine-treated fetal lambs, but did in salinetreated fetal lambs; sodium nitroprusside produced pulmonary vasodilation in both groups. Immediately after birth, at $140 \mathrm{~d}$ of gestation, during the 3-h study period, mean pulmonary arterial pressure did not decrease in $N^{\omega}$-nitro-L-arginine-treated lambs; the increase in pulmonary blood flow and decrease in pulmonary vascular resistance were markedly attenuated compared to saline-treated lambs. These hemodynamic derangements were reversed by $L$-arginine. There were no anatomic abnormalities in the pulmonary circulation. Chronic NO inhibition in utero reproduces many of the physiologic derangements of PPHN. Intrauterine events which result in endothelial dysfunction and inhibition of NO may produce the physiologic derrangements of PPHN. (J. Clin. Invest. 1994. 93:26752683.) Key words: arginine $\bullet$ endothelium-derived relaxing factor • persistent fetal circulation • pulmonary circulation • vascular endothelium
\end{abstract}

\section{Introduction}

With the onset of ventilation at birth, pulmonary arterial pressure and pulmonary vascular resistance decrease rapidly, and pulmonary blood flow increases 8 - to 10 -fold $(1,2)$. Although the mechanisms of these circulatory changes are not completely understood, the creation of an air-fluid interface, increased oxygen tension, rhythmic distension of the lungs, and the release of vasoactive substances all have important roles in this transition (2-7).

Address correspondence to Dr. Scott J. Soifer, Box 0106, M-646, University of California, San Francisco, 505 Parnassus Avenue, San Francisco, CA 94143-0106.

Received for publication 14 October 1993 and in revised form 10 January 1994.

J. Clin. Invest.

(c) The American Society for Clinical Investigation, Inc.

$0021-9738 / 94 / 06 / 2675 / 09 \quad \$ 2.00$

Volume 93, June 1994, 2675-2683
The clinical syndrome of persistent pulmonary hypertension of the newborn (PPHN $)^{1}$ is characterized by failure of the pulmonary circulation to undergo the normal transition from fetal to postnatal life. PPHN results in maintenance of high pulmonary vascular resistance, low pulmonary blood flow, and persistence of right-to-left shunting of blood through the foramen ovale and/or the ductus arteriosus. The syndrome is associated with a variety of conditions, including asphyxia, sepsis, and meconium aspiration; however, the etiology remains unknown $(8,9)$.

Recent reports indicate that exogenous inhaled nitric oxide (NO) produces potent and selective pulmonary vasodilation in some newborns with PPHN $(10,11)$. NO is endogenously synthesized by the vascular endothelium from L-arginine. It is an important mediator of resting pulmonary vascular tone in both the fetus and newborn (12-16). Once synthesized and released, NO diffuses into vascular smooth muscle cells where it activates soluble guanylate cyclase, the enzyme that catalyzes the production of cGMP from guanosine 5'-triphosphate. Activation of guanylate cyclase increases the concentration of cGMP, thus initiating a cascade that results in smooth muscle relaxation (17). In addition to its vasodilating activity, NO inhibits platelet aggregation and smooth muscle cell proliferation (18, 19). In animals, acute inhibition of NO synthesis attenuates the normal increase in pulmonary blood flow at birth, suggesting that $\mathrm{NO}$ activity is stimulated and may contribute to the decrease in pulmonary vascular resistance at birth $(15,16,20)$. However, acute inhibition of NO synthesis does not mimic the clinical syndrome of PPHN, because pulmonary arterial pressure still decreases normally (15). Therefore, the role of NO activity in the normal transition at birth and in the pathophysiology of PPHN remains unclear.

Several clinical and experimental observations suggest that intrauterine events may be related to the development of PPHN. For example, infants who die of PPHN often have marked pulmonary vascular structural changes, suggestive of a chronic intrauterine event $(21,22)$. In addition, in animal models, it requires chronic constriction or ligation of the ductus arteriosus to reproduce the physiologic and pathologic derangements of PPHN (23-26). The purpose of the present study was to determine the physiologic and pathologic derangements induced by chronic NO inhibition in utero in lambs and, thus, to investigate the potential role of impaired $\mathrm{NO}$ activity in the pathophysiology of PPHN. To determine the physiologic derangements caused by chronic NO inhibition in utero, the hemodynamic effects of a continuous $10-d$ infusion of $N^{\omega}$-nitroL-arginine (a competitive inhibitor of nitric oxide synthesis) or

1. Abbreviations used in this paper: $\mathrm{ACh}$, acetylcholine; PPHN, persistent pulmonary hypertension of the newborn; SNP, sodium nitroprusside. 
$0.9 \%$ saline alone ( $N^{\omega}$-nitro-L-arginine vehicle) in utero were determined in newborn lambs over the first $3 \mathrm{~h}$ after birth. To determine whether chronic NO inhibition in utero affects the vascular anatomy, pulmonary vascular morphometric analysis was performed in these lambs at autopsy.

\section{Methods}

\section{Surgical preparation}

11 mixed-breed Western ewes $(129.1 \pm 2.1 \mathrm{~d}$ of gestation, term $=145 \mathrm{~d})$ were operated on under sterile conditions with the use of local anesthesia ( $2 \%$ lidocaine hydrochloride), epidural anesthesia ( $4 \mathrm{ml}$ of $1 \%$ tetracaine hydrochloride), and intravenous sedation (50-100 mg of ketamine hydrochloride). A polyvinyl catheter was inserted into the maternal pedal vein. Through a small uterine incision, the fetal hindlimb was exposed. Fetal anesthesia consisted of local anesthesia with $1 \%$ lidocaine hydrochloride and $20 \mathrm{mg}$ ketamine hydrochloride i.m. Polyvinyl catheters were inserted into the fetal pedal artery and vein and were advanced to the descending aorta and the inferior vena cava, respectively. Through a second uterine incision, a left lateral thoracotomy was preformed in the fourth intercostal space. Succinylcholine hydrochloride (3-5 mg) was administrated intravenously to prevent fetal breathing movements. Polyvinyl catheters were then inserted into the internal thoracic artery and vein and advanced to the ascending aorta and right atrium, respectively. The pericardium was incised along the main pulmonary trunk. Three Teflon cannulae attached to polyvinyl catheters were then inserted, one into the proximal main pulmonary trunk, one into the main pulmonary artery distal to the ductus arteriosus, and one into the left atrium. An ultrasonic flow transducer (Transonic Systems, Ithaca, NY) was placed around the left pulmonary artery to measure left pulmonary arterial blood flow. An no. 8 French chest tube was placed in the pleural space. The thoracotomy incision was closed in layers. Warm saline was infused to replace the lost amniotic fluid and the uterine incision was closed. A polyvinyl catheter was placed in the amniotic cavity. The catheters were filled with heparin sodium, plugged, and brought to the skin along with the transducer cable, where they were protected in a pouch secured to the ewe's flank. After recovery from anesthesia, the ewe was returned to the cage. Antibiotics ( 2 million units of penicillin $\mathrm{G}$ procaine and $100 \mathrm{mg}$ of gentamicin sulfate) were administered intravenously to the ewe and into the amniotic cavity during surgery and daily thereafter. The chest tube was aspirated daily. All protocols were approved by the Committee on Animal Research of the University of California, San Francisco.

\section{Drug preparation}

Acetylcholine chloride (Iolab Corp., Claremont, CA) was diluted in sterile $\mathbf{0 . 9 \%}$ saline. Sodium nitroprusside (Abbott Laboratories, Chicago, IL) was diluted in $5 \%$ dextrose in water. $N^{\omega}$-nitro-L-arginine (Sigma Chemical Co., St. Louis, MO) was diluted in sterile $0.9 \%$ saline to a final concentration of $3 \mathrm{mg} / \mathrm{ml}$. L-arginine (Sigma Chemical Co.) was diluted in sterile $0.9 \%$ saline. Exosurf (Burroughs Wellcome Co., Research Triangle Park, NC) was reconstituted in sterile water. All solutions were prepared on the day of the study.

\section{Experimental protocol}

Fetal study. After a 48-h recovery, the fetuses were studied. The pregnant ewes stood quietly in a study cage with free access to food and water. After $30 \mathrm{~min}$, baseline measurements of the hemodynamic variables (pulmonary arterial pressure, systemic arterial pressure, heart rate, left pulmonary blood flow, left and right atrial pressures), amniotic pressure, and systemic arterial blood gases and $\mathrm{pH}$ were measured (baseline). An intravenous injection of acetylcholine ( $2 \mu \mathrm{g}, \mathrm{ACh})$ or a 5 -min infusion of sodium nitroprusside $(8 \mu \mathrm{g} / \mathrm{min}, \mathrm{SNP})$ was administered in random order. The hemodynamic variables were measured continuously and systemic arterial blood gases and $\mathrm{pH}$ were measured after a new steady state was achieved. 10-20 min was allowed between drugs for the hemodynamic variables to return to pre-injection values.
All measurements were then repeated and the other vasodilator was given. After recovery, the hemodynamic variables were measured and a continuous infusion of $N^{\omega}$-nitro-L-arginine $(0.3 \mathrm{mg} / \mathrm{min})$ or its vehicle $0.9 \%$ saline $(6 \mathrm{ml} / \mathrm{h})$ was begun into the distal main pulmonary artery via an ambulatory infusion pump (Dakman, Buffalo, NY). The infusion solution was changed daily. The dose of $N^{\omega}$-nitro-L-arginine was chosen after preliminary stuides showed that a 24-h infusion did not change resting pulmonary or systemic arterial pressure, but completely blocked the pulmonary vasodilating effects of $\mathrm{ACh}$ (a vasodilator dependent upon endogenous NO production).

The fetal study was repeated at $140 \mathrm{~d}$ of gestation. After recovery, the pregnant ewe was given epidural anesthesia $(4 \mathrm{ml}$ of $1 \%$ tetracaine hydrochloride) and intravenous sedation (50-100 mg ketamine hydrochloride). Ketamine hydrochloride $(20 \mathrm{mg})$ and succinylcholine hydrochloride $(5 \mathrm{mg})$ were given to the fetus, which was then intubated with a 4.5-mm o.d. endotracheal tube. The lambs were delivered via cesarean section. Tracheal fluid was drained by gravity and Exosurf $(10 \mathrm{ml})$ was instilled into the airway over $10 \mathrm{~min}$ to preclude the possibility of surfactant deficiency. The lamb was mechanically ventilated with a pediatric time-cycled pressure-limited ventilator (Healthdyne, Marietta, GA). The umbilical cord was clamped and ligated after initiation of mechanical ventilation. After delivery, thic ewe was given a lethal dose of pentobarbital sodium followed by bilateral thoracotomy.

Newborn study. The hemodynamic variables were monitored continuously throughout the 3-h study period, and measured at $15,30,45$, 60,120 , and $180 \mathrm{~min}$. Systemic arterial blood gases were obtained from the ascending and descending aorta every $15 \mathrm{~min}$ over the first hour, and every $30 \mathrm{~min}$ thereafter. Ventilation was adjusted to maintain nor-

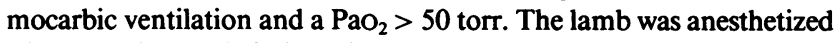
with a continuous infusion of ketamine hydrochloride $(\sim 1 \mathrm{mg} / \mathrm{kg}$ per min); normothermia was achieved with heating lamps. Sodium bicarbonate was given intermittently over the first 30 min to maintain a systemic arterial $\mathrm{pH}>7.30 .0 .9 \%$ saline was given intermittently to maintain atrial pressures $>2 \mathrm{mmHg}$. At $3 \mathrm{~h}$, L-arginine $(150 \mathrm{mg} / \mathrm{kg})$ was infused intravenously over $5 \mathrm{~min}$, and the hemodynamic variables and systemic arterial blood gases and $\mathrm{pH}$ were measured 15 min later, when a new steady state was achieved. The lamb was then given a lethal dose of pentobarbital sodium followed by bilateral thoracotomy. At autopsy, catheter placement was confirmed and closure of the ductus arteriosus was confirmed.

Pulmonary vascular morphology. The trachea and lungs were removed from the chest wall cavity through a midline sternotomy and frozen. They were later thawed by immersion in a $40^{\circ} \mathrm{C}$ water bath as previously described (27). The pulmonary arteries were injected with a warm barium gelatin suspension $(400 \mathrm{ml}$ of micropaque powder [Nicholas Picker Co., Stoughton, MA], $50 \mathrm{~g}$ of gelatin, Bloom 8-G [Fisher Scientific Co., Fairlawn, NJ], $500 \mathrm{ml}$ of distilled water, and a few crystals of phenol) at $75-\mathrm{cm}$ water pressure and $60^{\circ} \mathrm{C}$ for $2 \mathrm{~min}$ using the technique of Reid adapted from the method of Short (28). Next the trachea was cannulated and the lungs were infused with $10 \%$ neutral buffered formalin at $25-\mathrm{cm} \mathrm{H}_{2} \mathrm{O}$ pressure until completely inflated, and then immersed in fixative for at least $24 \mathrm{~h}$. Lungs were then serially sectioned at 2- to 3-mm intervals, and the slices were arranged in a single layer under a plastic transparency imprinted with equidistant numbered points. Five blocks of parencymal tissue were selected from each animal using a random number table. Tissue blocks were processed through graded alcohols, embedded in paraffin, and sectioned at $4 \mu \mathrm{m}$. Tissue sections were stained with hematoxylin and eosin, and by Miller's elastic Van Gieson method to demonstrate elastic tissue and smooth muscle.

For analysis, arteries were categorized according to their position in the respiratory tree. Preacinar arteries were divided into those accompanying bronchioles and terminal bronchioles, and intracinar arteries were grouped into those accompanying respiratory bronchioles, alveolar ducts, and those within the alveolar wall. All microscopic sections were examined without knowledge of the experimental group to which the lamb belonged. 


\section{Measurements}

Pulmonary and systemic arterial, right and left atrial pressures were measured by Statham P23Db pressure transducers (Statham Instruments, Hato Rey, PR). Mean pressures were obtained by electrical integration. All pressures obtained in utero were zeroed against the amniotic cavity pressure. Heart rate was measured by a cardiotachometer triggered from the phasic systemic arterial pressure pulse wave. Left pulmonary blood flow was measured on an ultrasonic flow meter (Transonic Systems). All hemodynamic variables were continuously recorded on a Gould multichannel electrostatic recorder (Gould Inc., Cleveland, $\mathrm{OH}$ ). Systemic arterial blood gases and $\mathrm{pH}$ were measured on a Corning $158 \mathrm{pH} / \mathrm{blood}$ gas analyzer (Corning Medical and Scientific, Medfield, MA). Left pulmonary vascular resistance was calculated using standard formulas. The fetal weight before beginning the infusions was estimated as a percentage of birth weight using standardized fetal sheep growth charts (29).

\section{Statistical analysis}

The means \pm standard deviation and standard error were calculated for the hemodynamic variables, systemic arterial blood gases, and $\mathrm{pH}$ during all experimental conditions. For the fetal study, the effects of each vasoactive stimulus ( $N^{\omega}$-nitro-L-arginine, $0.9 \%$ saline, $\mathrm{ACh}, \mathrm{SNP}$, and L-arginine) on these variables were compared to their previous steadystate condition by the paired $t$ test. The effects of each vasoactive stimulus on pulmonary vascular resistance was compared to their previous steady-state condition by the Wilcoxin signed-rank test. The percent change in pulmonary arterial pressure and absolute change in pulmonary blood flow induced by these stimuli were compared between study groups by the unpaired $t$ test. The percent change in pulmonary vascular resistance induced by these stimuli were compared between study groups by the Mann-Whitney U test.

For the newborn study, comparisons of these variables over time within each study group was made by ANOVA for repeated measures. Comparisons of these variables between study groups were made by the unpaired $t$ test. Comparisons of pulmonary vascular resistance between study groups were made by the Mann-Whitney $U$ test.

The distribution of vessels by wall structure was compared by $\chi^{2}$ analysis except for small cell frequencies where Fisher's exact test was used. A $P<0.05$ was considered statistically significant.

\section{Results}

Fetal study. The baseline hemodynamic variables and systemic arterial blood gases and $\mathrm{pH}$ were similar between the two groups, and within the normal range for the laboratory.

Before beginning the infusion $\left(N^{\omega}\right.$-nitro-L-arginine or $0.9 \%$ saline), ACh decreased mean pulmonary arterial pressure, pulmonary vascular resistance, and mean systemic arterial pres- sure, and increased left pulmonary blood flow (Table I). SNP produced similar hemodynamic effects, but did not increase left pulmonary blood flow (Fig. 1).

The infusion of $N^{\omega}$-nitro-L-arginine or $0.9 \%$ saline did not change any of the hemodynamic variables. After the infusions, at $140 \mathrm{~d}$ of gestation, the baseline hemodynamic variables and systemic arterial blood gases and $\mathrm{pH}$ were similar between the two groups. After the $N^{\omega}$-nitro-L-arginine infusion, an injection of ACh did not change any of the hemodynamic variables; however, it continued to produce pulmonary vasodilation after the saline infusions (Table II). An infusion of SNP decreased mean pulmonary arterial pressure and pulmonary vascular resistance similarly in the two groups. SNP induced a greater increase in left pulmonary blood flow in the lambs receiving $N^{\omega}$-nitro-L-arginine (Fig. 1).

Newborn study. In the $N^{\omega}$-nitro-L-arginine-treated lambs, the mean pulmonary arterial pressure did not change from in utero values over the 180 -min study period after birth. In contrast, the mean pulmonary arterial pressure decreased significantly in the saline-treated lambs over this period (Tables III and IV, Fig. 2). In the $N^{\omega}$-nitro-L-arginine-treated lambs, the increase in left pulmonary blood flow and decrease in left pulmonary vascular resistance were substantially less than in the saline-treated lambs. The ratio of mean pulmonary arterial pressure to systemic arterial pressure decreased over the first 30 min in both groups of lambs (Fig. 3). However, in the $N^{\omega}$-nitro$\mathrm{L}$-arginine-treated lambs, it increased back to in utero values (1.0); it continued to decrease to 0.55 in the saline-treated lambs. Systemic arterial $\mathrm{Po}_{2}$ increased after birth in both groups of lambs. There were no differences in ascending and descending aortic saturations. Two $N^{\omega}$-nitro-L-argininetreated lambs had hypoxemia $\left(\mathrm{PaO}_{2}<45\right.$ torr $)$ that was minimally responsive to oxygen therapy. Their mean pulmonary arterial pressure was equal to or intermittently greater than the mean systemic arterial pressure. These lambs had right to left atrial shunting demonstrated by echocardiography.

180 min after delivery, the mean pulmonary arterial pressure, left pulmonary vascular resistance, and the ratio of mean pulmonary arterial pressure to systemic arterial pressure were all higher, and left pulmonary blood flow was lower in the $N^{\omega}$-nitro-L-arginine-treated lambs as compared to the salinetreated lambs $(P<0.05)$. Systemic arterial pressure, heart rate, left and right atrial pressures, and systemic arterial blood gases and $\mathrm{pH}$ were similar between the groups.

The intravenous infusion of $\mathrm{L}$-arginine reversed the pulmo-

Table I. In Utero Vasodilator Responses before $N^{\omega}$-Nitro-L-Arginine or Saline Infusions

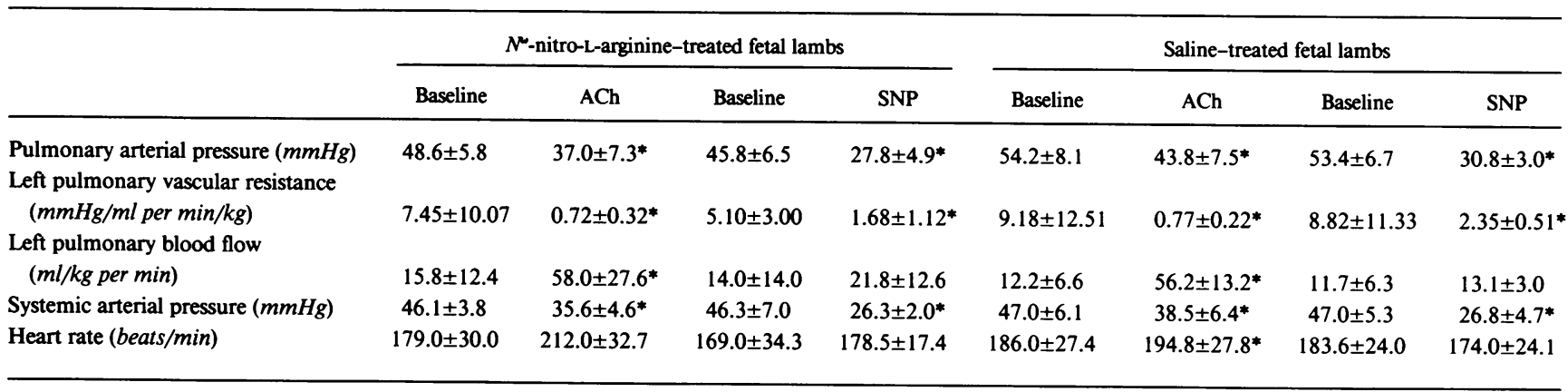

Values are mean $\pm \mathrm{SD} . \quad * P<0.05$ vs. previous baseline. 


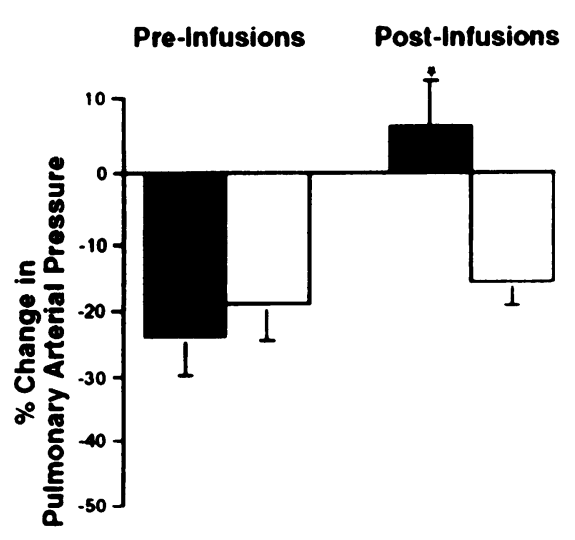

N"-nitro-L-arginine Animals

Saline Animals

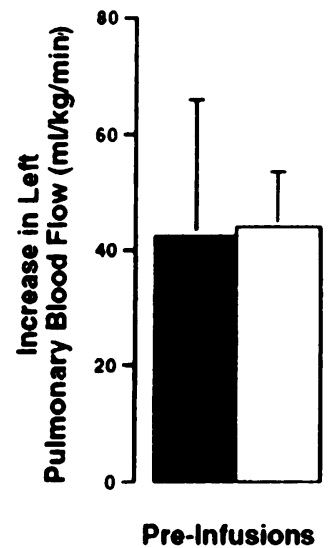

Pre-Infusions

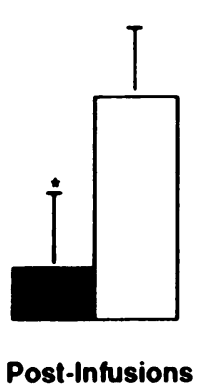

Post-Infusions

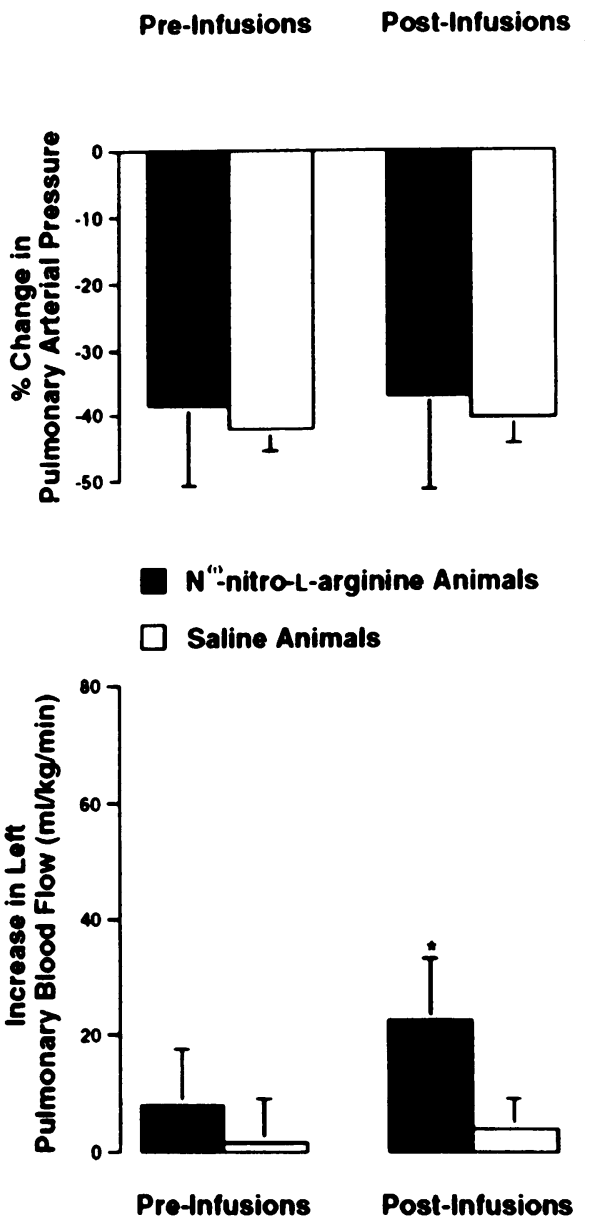

Figure 1. The percent change in mean pulmonary arterial pressure (top) and absolute change in left pulmonary blood flow (bottom) induced by $\mathrm{ACh}(A)$ and $\operatorname{SNP}(B)$ before and after the infusions of $N^{\omega}{ }^{\omega}$-nitro-L-arginine or saline. $N^{\omega}$-nitro-L-arginine lambs ( $n$ $=6)$; saline lambs $(n=5)$.

Values are mean \pm SD. ${ }^{*} P$ $<0.05$ vs. saline lambs. nary hypertension in the $N^{\omega}$-nitro-L-arginine-treated lambs (Fig. 4). It also decreased mean systemic arterial pressure (from $54.8 \pm 10.6$ to $48.4 \pm 7.5, P<0.05$ ). Heart rate, left and right atrial pressure, and systemic arterial blood gases and $\mathrm{pH}$ did not change. In the saline-treated lambs, the intravenous infusion of L-arginine did not change any of the hemodynamic variables. After the infusion of $\mathrm{L}$-arginine, mean pulmonary arterial pressure, left pulmonary vascular resistance, and left pulmonary blood flow were similar between the 2 groups (Fig. 4).
There were no differences in birth weight $(3.76 \pm 1.0 \mathrm{~kg}$ for $N^{\omega}$-nitro-L-arginine vs. $3.82 \pm 0.3 \mathrm{~kg}$ for saline), lung weight, sex distribution, amount of sodium bicarbonate or volume administered, or mean airway pressure utilized. The $N^{\omega}$-nitro-L-arginine-treated lambs required a higher inspired oxygen concentration to maintain ${\mathrm{a} \mathrm{PaO}_{2}}_{2} 50$ torr $(P<0.05)$. At autopsy, the ductus arteriosus was closed in all lambs.

There were no differences in the proportion of muscularized pulmonary arteries at any level between the two groups (Tables V and VI).

Table II. In Utero Vasodilator Responses after $N^{\omega}$-Nitro-L-Arginine or Saline Infusions

\begin{tabular}{|c|c|c|c|c|c|c|c|c|}
\hline & \multicolumn{4}{|c|}{$N^{\omega}$-nitro-L-arginine-treated fetal lambs } & \multicolumn{4}{|c|}{ Saline-treated fetal lambs } \\
\hline & Baseline & $\mathrm{ACh}$ & Baseline & SNP & Baseline & $\mathrm{ACh}$ & Baseline & SNP \\
\hline Pulmonary arterial pressure $(\mathrm{mmHg})$ & $51.8 \pm 8.8$ & $56.1 \pm 15.3$ & $52.1 \pm 9.0$ & $32.7 \pm 5.1^{*}$ & $54.0 \pm 11.8$ & $44.8 \pm 11.1^{*}$ & $55.2 \pm 10.9$ & $33.4 \pm 6.6^{*}$ \\
\hline \multicolumn{9}{|l|}{ Left pulmonary vascular resistance } \\
\hline$(\mathrm{mmHg} / \mathrm{ml} \mathrm{per} \mathrm{min} / \mathrm{kg})$ & $13.84 \pm 6.09$ & $17.66 \pm 25.10$ & $17.58 \pm 10.16$ & $2.26 \pm 2.42^{*}$ & $7.44 \pm 3.87$ & $1.02 \pm 0.61^{*}$ & $10.76 \pm 8.11$ & $2.78 \pm 1.49^{*}$ \\
\hline \multicolumn{9}{|l|}{ Left pulmonary blood flow } \\
\hline ( $\mathrm{ml} / \mathrm{kg}$ per $\mathrm{min})$ & $7.0 \pm 5.1$ & $15.8 \pm 15.7$ & $5.5 \pm 3.7$ & $27.8 \pm 10.4^{*}$ & $9.3 \pm 6.0$ & $47.6 \pm 14.5^{*}$ & $8.9 \pm 5.2$ & $12.9 \pm 5.8$ \\
\hline Systemic arterial pressure $(\mathrm{mmHg})$ & $52.5 \pm 7.2$ & $52.3 \pm 8.8$ & $51.2 \pm 6.9$ & $31.1 \pm 5.4^{*}$ & $51.0 \pm 9.6$ & $42.2 \pm 9.7^{*}$ & $46.8 \pm 2.2$ & $28.3 \pm 1.3^{*}$ \\
\hline Heart rate (beats/min) & $184.0 \pm 18.1$ & $186.0 \pm 19.4$ & $182.0 \pm 17.9$ & $186.0 \pm 16.7$ & $181.2 \pm 14.0$ & $197.2 \pm 23.2$ & $183.6 \pm 15.7$ & $171.6 \pm 8.5$ \\
\hline
\end{tabular}

Values are mean $\pm \mathrm{SD} . \quad * P<0.05$ vs. previous baseline. 


\begin{tabular}{|c|c|c|c|c|c|c|c|}
\hline & \multicolumn{7}{|c|}{ Time after delivery } \\
\hline & \multicolumn{7}{|c|}{$\min$} \\
\hline & 0 & 15 & 30 & 45 & 60 & 120 & 180 \\
\hline Pulmonary arterial pressure $(\mathrm{mmHg})$ & $53.2 \pm 10.2$ & $55.6 \pm 18.0$ & $50.5 \pm 15.8$ & $55.0 \pm 13.9$ & $52.5 \pm 15.9$ & $53.0 \pm 10.4$ & $52.0 \pm 9.9$ \\
\hline $\begin{array}{l}\text { Left pulmonary vascular resistance } \\
\quad(\mathrm{mmHg} / \mathrm{ml} \mathrm{per} \mathrm{min} / \mathrm{kg})\end{array}$ & $10.25 \pm 5.86^{\ddagger}$ & $1.21 \pm 0.94^{*}$ & $1.05 \pm 0.37$ & $1.34 \pm 0.47$ & $1.34 \pm 0.48$ & $1.75 \pm 0.99$ & $1.74 \pm 1.59$ \\
\hline Left pulmonary blood flow & & & & & & & \\
\hline (ml/kg per min) & $8.8 \pm 8.7^{\ddagger}$ & $59.7 \pm 31.5^{*}$ & $50.5 \pm 19.7$ & $44.5 \pm 19.2$ & $42.6 \pm 15.4$ & $37.2 \pm 16.3$ & $43.4 \pm 20.3$ \\
\hline Systemic arterial pressure $(\mathrm{mmHg})$ & $53.6 \pm 8.9$ & $68.8 \pm 12.0^{* \pm}$ & $66.0 \pm 12.2^{\ddagger}$ & $59.7 \pm 8.3^{* \pm}$ & $59.0 \pm 11.9^{\ddagger}$ & $52.6 \pm 9.3^{*}$ & $52.6 \pm 10.0$ \\
\hline Heart rate $($ beats $/ \mathrm{min})$ & $185.0 \pm 20.6$ & $181.7 \pm 18.3$ & $180.3 \pm 27.9$ & $169.0 \pm 28.8$ & $179.6 \pm 29.1$ & $173.1 \pm 28.2$ & $167.8 \pm 33.2$ \\
\hline Left atrial pressure $(\mathrm{mmHg})$ & $2.3 \pm 1.2$ & $2.8 \pm 2.2$ & $3.0 \pm 2.9$ & $2.4 \pm 2.3$ & $2.0 \pm 1.7$ & $2.1 \pm 1.7$ & $2.1 \pm 1.8$ \\
\hline Right atrial pressure $(\mathrm{mmHg})$ & $2.0 \pm 0.7$ & $5.0 \pm 2.0$ & $6.3 \pm 3.3$ & $5.8 \pm 2.8$ & $5.2 \pm 2.9$ & $4.5 \pm 2.5$ & $5.3 \pm 3.1$ \\
\hline $\mathrm{pH}$ (units) & $7.33 \pm 0.03$ & $7.30 \pm 0.16$ & $7.37 \pm 0.08$ & $7.41 \pm 0.05$ & $7.37 \pm 0.09$ & $7.38 \pm 0.04$ & $7.39 \pm 0.06$ \\
\hline $\mathrm{PaCO}_{2}$ (torr) & $51.3 \pm 4.2^{\ddagger}$ & $43.3 \pm 10.7^{\ddagger}$ & $34.5 \pm 8.3$ & $37.7 \pm 8.7$ & $35.3 \pm 7.1$ & $35.1 \pm 5.4$ & $33.0 \pm 8.3$ \\
\hline $\mathrm{PaO}_{2}$ (torr) & $21.4 \pm 2.1$ & $78.8 \pm 48.5^{*}$ & $67.0 \pm 29.9$ & $57.7 \pm 38.7$ & $50.0 \pm 21.5$ & $44.2 \pm 19.1$ & $50.8 \pm 22.9$ \\
\hline
\end{tabular}

Values are mean \pm SD. ${ }^{*} P<0.05$ vs. previous column (ANOVA); ${ }^{\ddagger} P<0.05$ vs. $180 \mathrm{~min}$ (ANOVA).

\section{Discussion}

We report that chronic in utero inhibition of NO in fetal lambs reproduces the physiologic derangements of PPHN after birth. Before delivery, the $N^{\omega}$-nitro-L-arginine-treated lambs had a selective impairment of endothelium-derived NO-dependent pulmonary vasodilation; the pulmonary vasodilating effects of ACh did not occur, and the pulmonary vasodilating effects of SNP were normal. After birth, mean pulmonary arterial pressure did not decrease in the $N^{\omega}$-nitro-L-arginine-treated lambs, and often exceeded systemic arterial pressure. Left pulmonary vascular resistance initially decreased after birth, but then tended to increase over the 3-h study period, becoming significantly greater than control lambs $30 \mathrm{~min}$ after birth. Similarly, left pulmonary blood flow initially increased after birth, but then tended to decrease becoming significantly lower than con- trol lambs $30 \mathrm{~min}$ after birth. In addition, these physiologic derangements were corrected by reversing the NO inhibition with administration of $\mathrm{L}$-arginine. This is the first animal preparation to produce the physiologic derangements of PPHN, without producing fetal pulmonary hypertension or the associated pulmonary vascular remodeling. These data implicate a crucial role for NO activity in the transitional circulation, particularly in the period immediately after the initial rapid fall in pulmonary vascular resistance after birth. In addition, this study suggests that in utero events resulting in endothelial dysfunction and impairment of NO activity may produce the physiologic derangements of PPHN.

To study the effects of nitric oxide inhibition in utero, $N^{\omega}-$ nitro-L-arginine was continuously infused for $10 \mathrm{~d}$. $N^{\omega}$-nitro-Larginine is an analogue of $\mathrm{L}$-arginine, with a chemically altered guanidino moiety. Nitric oxide is synthesized from L-arginine

Table IV. Hemodynamic Changes after Birth in Saline-treated Lambs

\begin{tabular}{|c|c|c|c|c|c|c|c|}
\hline & \multicolumn{7}{|c|}{ Time after delivery } \\
\hline & \multicolumn{7}{|c|}{$\min$} \\
\hline & 0 & 15 & 30 & 45 & 60 & 120 & 180 \\
\hline Pulmonary arterial pressure $(\mathrm{mmHg})$ & $52.2 \pm 6.5^{\ddagger}$ & $65.2 \pm 11.7^{* \pm}$ & $56.0 \pm 9.8^{* \neq}$ & $54.6 \pm 6.1^{\ddagger}$ & $47.0 \pm 6.7^{\ddagger}$ & $41.4 \pm 2.9^{\ddagger}$ & $34.4 \pm 4.0$ \\
\hline \multicolumn{8}{|l|}{ Left pulmonary vascular resistance } \\
\hline$(\mathrm{mmHg} / \mathrm{ml} \mathrm{per} \mathrm{min} / \mathrm{kg})$ & $8.52 \pm 3.50^{\ddagger}$ & $0.69 \pm 0.16^{*}$ & $0.55 \pm 0.08$ & $0.47 \pm 0.04$ & $0.45 \pm 0.06$ & $0.49 \pm 0.19$ & $0.38 \pm 0.13$ \\
\hline \multicolumn{8}{|l|}{ Left pulmonary blood flow } \\
\hline$(\mathrm{ml} / \mathrm{kg} \mathrm{per} \mathrm{min})$ & $6.9 \pm 3.7^{\ddagger}$ & $86.9 \pm 20.6^{*}$ & $92.5 \pm 23.0$ & $104.2 \pm 22.2$ & $95.1 \pm 19.3$ & $82.1 \pm 32.3$ & $84.3 \pm 31.6$ \\
\hline Systemic arterial pressure $(\mathrm{mmHg})$ & $50.4 \pm 6.7$ & $69.6 \pm 9.0^{*}$ & $69.6 \pm 3.8$ & $68.7 \pm 4.0$ & $67.5 \pm 7.5$ & $63.2 \pm 10.4$ & $63.0 \pm 11.1$ \\
\hline Heart rate (beats/min) & $176.0 \pm 11.4^{\ddagger}$ & $190.4 \pm 22.1^{\ddagger}$ & $184.0 \pm 26.0^{\ddagger}$ & $193.3 \pm 15.2^{\ddagger}$ & $184.2 \pm 20.3^{\ddagger}$ & $169.0 \pm 23.0$ & $161.2 \pm 22.9$ \\
\hline Left atrial pressure $(\mathrm{mmHg})$ & $3.0 \pm 2.9$ & $6.0 \pm 2.7$ & $5.0 \pm 1.4$ & $4.5 \pm 0.7$ & $4.0 \pm 1.0$ & $5.0 \pm 2.7$ & $4.8 \pm 2.2$ \\
\hline Right atrial pressure $(\mathrm{mmHg})$ & $2.9 \pm 1.2$ & $4.8 \pm 2.1$ & $4.6 \pm 0.9$ & $4.7 \pm 1.2$ & $5.0 \pm 2.1$ & $4.4 \pm 1.8$ & $4.6 \pm 2.3$ \\
\hline $\mathrm{pH}$ (units) & $7.37 \pm 0.03$ & $7.21 \pm 0.14^{* \pm}$ & $7.23 \pm 0.09^{\ddagger}$ & $7.29 \pm 0.08^{\ddagger}$ & $7.36 \pm 0.05^{\ddagger}$ & $7.42 \pm 0.06$ & $7.40 \pm 0.06$ \\
\hline $\mathrm{PaCO}_{2}$ (torr) & $49.0 \pm 1.0$ & $50.7 \pm 27.4$ & $55.2 \pm 16.3$ & $52.0 \pm 5.6$ & $41.4 \pm 7.9$ & $35.8 \pm 7.9$ & $34.8 \pm 7.3$ \\
\hline $\mathrm{PaO}_{2}$ (torr) & $20.0 \pm 2.7^{\ddagger}$ & $102.0 \pm 65.5^{* \pm}$ & $98.0 \pm 63.4$ & $70.0 \pm 14.1$ & $76.8 \pm 37.8$ & $63.2 \pm 18.4$ & $66.8 \pm 17.7$ \\
\hline
\end{tabular}

Values are mean $\pm \mathrm{SD} .{ }^{*} P<0.05$ vs. previous column (ANOVA); ${ }^{\ddagger} P<0.05$ vs. $180 \mathrm{MIN}$ (ANOVA). 
A

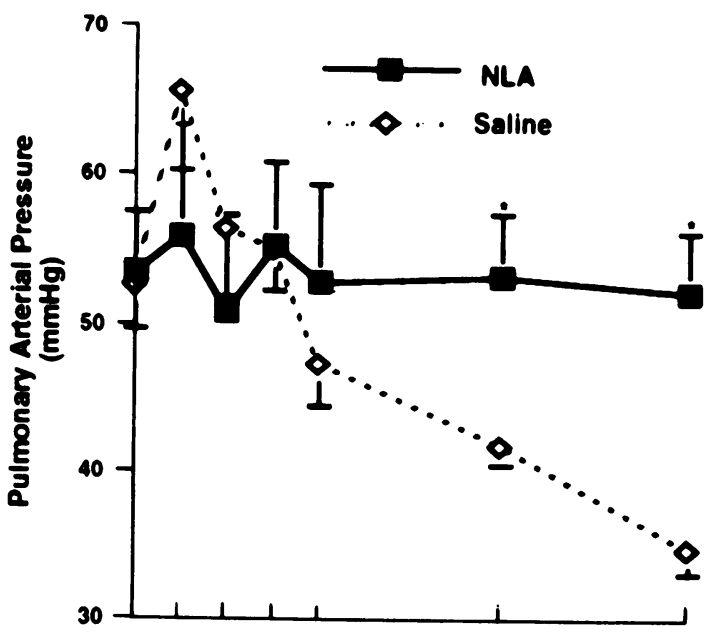

B

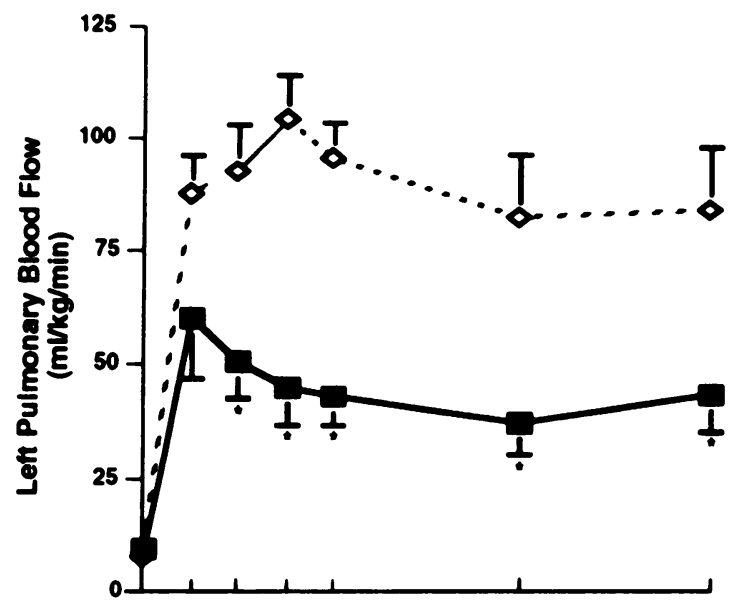

C

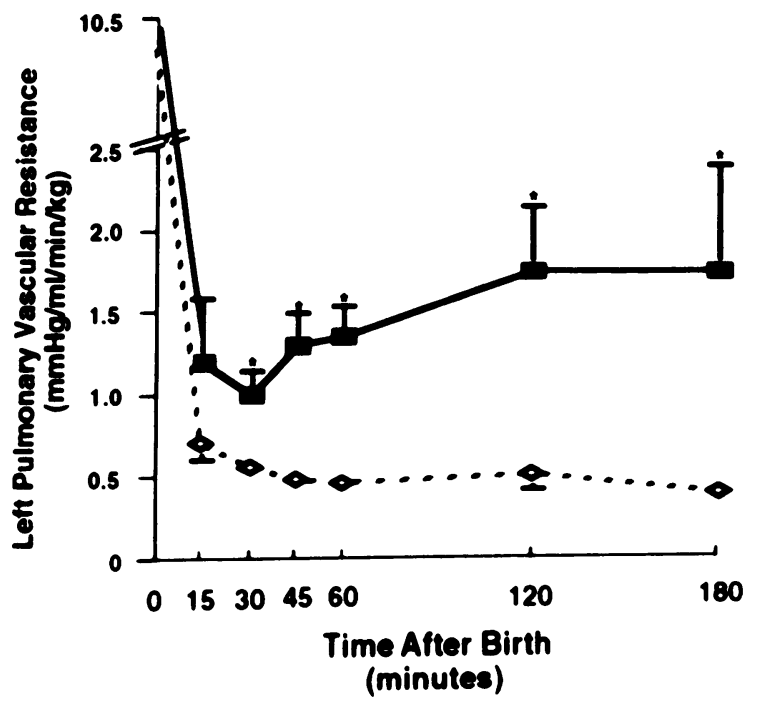

Figure 2. Changes in mean pulmonary arterial pressure $(A)$, left pulmonary blood flow $(B)$, and left pulmonary vascular resistance $(C)$ after birth following in utero infusions of $N^{\omega}$-nitro-L-arginine ( $N L A$; solid lines, $n=6$ ) or saline (dashed lines, $n=5$ ). Values are mean \pm SEM. ${ }^{*} P<0.05$ vs. saline lambs.

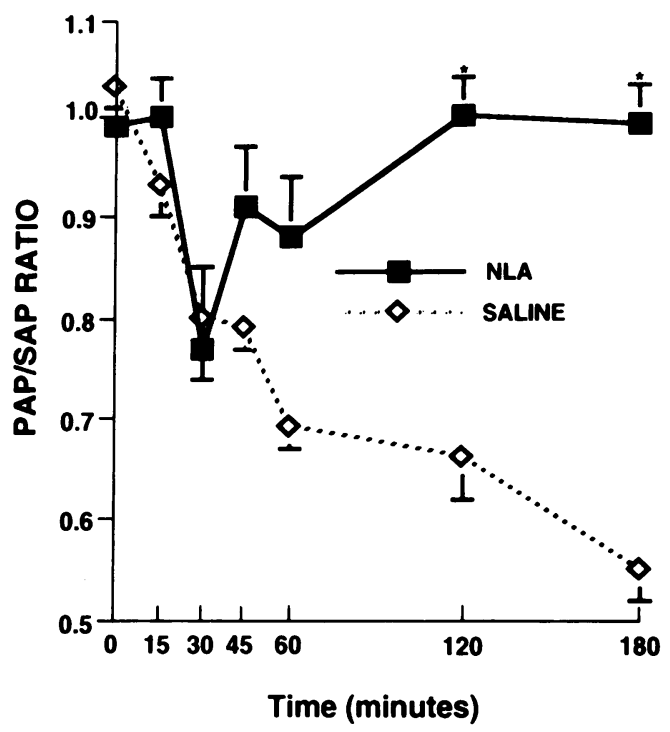

Figure 3. Changes in the ratio of mean pulmonary arterial to mean systemic arterial pressure after birth after in utero infusions of $N^{\omega}$ nitro-L-arginine ( $N L A$; solid lines, $n=6$ ) or saline (dashed lines, $n$ $=5$ ). Values are mean \pm SEM. ${ }^{*} P<0.05$ vs. saline lambs.

by the oxidation of a guanidino-nitrogen moiety of L-arginine (13). Both in vitro and in vivo, $N^{\omega}{ }^{\omega}$-nitro-L-arginine produces a competitive and stereospecific inhibition of this oxidation (14, 27). The dose of $N^{\omega}$-nitro-L-arginine was chosen after several preliminary studies showed that an infusion of $0.3 \mathrm{mg} / \mathrm{min}$ did not change baseline fetal hemodynamics, and completely blocked the pulmonary vasodilating response of acetylcholine (a vasodilator dependent upon endogenous NO production) after $24 \mathrm{~h}$. This ensured that our findings were independent of chronic fetal hypertension (a known animal model of PPHN), and that NO inhibition was achieved quickly. To ensure selective nitric oxide inhibition, the response of SNP (a vasodilator which releases its own NO) was also evaluated (17). After the 10-d infusion of $N^{\omega}$-nitro-L-arginine, the response of $\mathrm{ACh}$ was blocked, but the response to SNP was not. In fact, the increase in left pulmonary blood flow in response to sodium nitroprusside was augmented in the lambs receiving $N^{\omega}$-nitro-L-arginine. This most likely represents an enhanced sensitivity of soluble guanylate cyclase to nitrovasodilators after chronic NO inhibition, which has been previously reported $(30,31)$.

Basal NO release is important in maintaining the resting pulmonary vascular tone of the fetus and newborn lamb; however, the role of NO release during the transitional circulation remains unclear (14-16). In a previous study by Abman et al. (15), $N^{\omega}$-nitro-L-arginine $(1 \mathrm{mg} / \mathrm{min})$ was infused for $30 \mathrm{~min}$ into the pulmonary artery of late gestation fetal sheep immediately before cesarean-section delivery. This acute inhibition of NO attenuated the normal increase in pulmonary blood flow at birth, suggesting that nitric oxide activity contributes to the decrease in pulmonary vascular resistance at birth. However, the dose of $N^{\omega}$-nitro-L-arginine used increased baseline pulmonary arterial pressure and pulmonary vascular resistance. In addition, the decrease in pulmonary arterial pressure was not attenuated after birth. In the present study, the low dose of $N^{\omega}$-nitro-L-arginine used $(0.3 \mathrm{mg} / \mathrm{min})$ did not increase baseline pulmonary arterial pressure or pulmonary vascular resistance, but completely blocked the decrease in pulmonary arterial pressure, and attenuated the decrease in pulmonary vascular resistance after birth. Therefore, this study clearly defines 


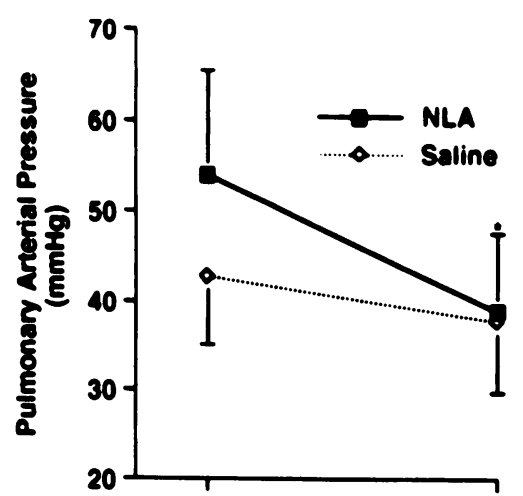

B

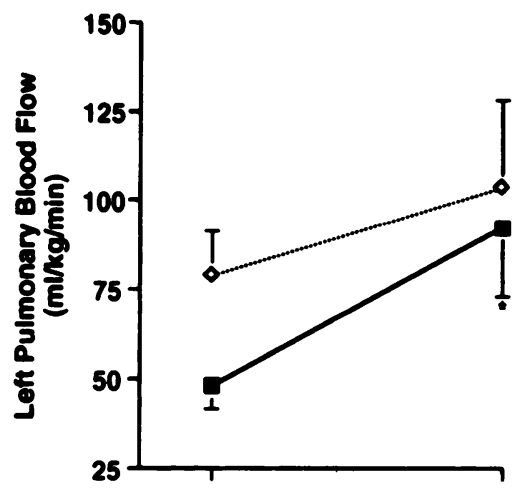

C

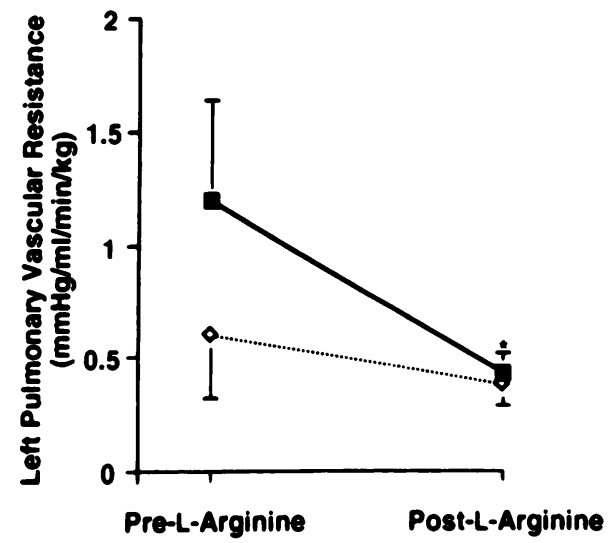

Figure 4. The changes in mean pulmonary arterial pressure $(A)$, left pulmonary blood flow $(B)$, and left pulmonary vascular resistance $(C)$ induced by L-arginine $(150 \mathrm{mg} / \mathrm{kg}) 3 \mathrm{~h}$ after birth, after in utero infusions of $N^{\omega}$-nitro-L-arginine ( $N L A$; solid lines, $\left.n=6\right)$ or saline (dashed lines, $n=5$ ). Values are mean \pm SEM. ${ }^{*} P<0.05$ vs. pre-L-Arginine. the crucial role of NO activity in the transition of the pulmonary circulation at birth.

In the previous study by Abman et al. (15), acute NO inhibition did not alter the immediate decrease in pulmonary vascular resistance that occurs within the first minute after birth, but attenuated the further decrease over the subsequent $60 \mathrm{~min}$. In the present study, the immediate decrease in pulmonary vascular resistance and increase in pulmonary blood flow was not inhibited by chronic $N^{\omega}$-nitro-L-arginine infusions (Fig. 2). However, 30 min later, differences in pulmonary vascular resistance and pulmonary blood flow appeared between the two groups and persisted for the 3-h study period. Increased blood flow and the associated increased shear stress are potent stimuli of nitric oxide release (32-34). This study suggests that, after an initial NO-independent decrease in pulmonary vascular resistance, the resultant increase in pulmonary blood flow stimulates NO release, which is critical in maintaining the further decrease in pulmonary vascular resistance after birth. Whether mechanical factors, the creation of an air-fluid interface, or changes in other vasoactive substances are responsible for the immediate decrease in pulmonary vascular resistance remains unclear. Leffler et al. (5) found that cyclooxygenase inhibition also did not alter the immediate decrease in pulmonary vascular resistance at birth, but attenuated the further decrease over the subsequent 10-20 min. This study did not investigate the relative roles of prostaglandins and NO in maintaining pulmonary vasodilation after birth. However, cyclooxygenase inhibition alone does not produce persistent elevation of pulmonary arterial pressure or decrease in pulmonary blood flow after birth $(5,35)$.

Previous animal preparations have reproduced the physiologic and pathologic derangements of persistent pulmonary hypertension. These preparations include pharmacological or mechanical constriction or occlusion of the ductus arteriosus (26-29). Although the models are varied, they all produced chronic fetal pulmonary hypertension. Chronic fetal hypoxemia has not reliably reproduced either the physiologic or pathologic derangements of persistent pulmonary hypertension $(36,37)$. This is the first animal preparation that reproduces the physiologic derangements of persistent pulmonary hypertension, without producing pulmonary vascular structural remodeling. In addition, this is the first animal preparation that reproduces the physiologic derangements of persistent pulmonary hypertension without producing chronic fetal pulmonary hypertension, suggesting another etiology for PPHN, i.e., NO inhibition.

In vitro, NO inhibits smooth muscle cell mitogenesis and proliferation (19). However, in the present study, chronic NO

Table V. Number and Percentage of Fully Muscular, Partially Muscular, and Nonmuscular Pulmonary Arteries Associated with Preacinar Airways in Newborn Lambs after $N^{w}$-Nitro-L-Arginine or Saline Infusions

\begin{tabular}{|c|c|c|c|c|c|c|}
\hline & \multicolumn{3}{|c|}{ Bronchioles } & \multicolumn{3}{|c|}{ Terminal bronchioles } \\
\hline & $\begin{array}{c}\text { Degree of } \\
\text { muscularization }\end{array}$ & $\begin{array}{l}\text { No. of } \\
\text { arteries }\end{array}$ & $\begin{array}{c}\text { Percent } \\
\text { distribution }\end{array}$ & $\begin{array}{c}\text { Degree of } \\
\text { muscularization }\end{array}$ & $\begin{array}{l}\text { No. of } \\
\text { arteries }\end{array}$ & $\begin{array}{c}\text { Percent } \\
\text { distribution }\end{array}$ \\
\hline \multirow{3}{*}{$N^{\omega}$-nitro-L-arginine infusions $(n=5)$} & Fully & 52 & 100 & Fully & 45 & 90 \\
\hline & Partially & 0 & 0 & Partially & 4 & 8 \\
\hline & Absent & 0 & 0 & Absent & 1 & 2 \\
\hline \multirow{3}{*}{ Saline infusions $(n=4)$} & Fully & 42 & 100 & Fully & 40 & 95 \\
\hline & Partially & 0 & 0 & Partially & 2 & 3.4 \\
\hline & Absent & 0 & 0 & Absent & 1 & 1.6 \\
\hline
\end{tabular}


Table VI. Number and Percentage of Fully Muscular, Partially Muscular, and Nonmuscular Pulmonary Arteries Associated with Intraacinar Airways in Newborn Lambs after $N^{\omega}$-Nitro-L-Arginine or Saline Infusions

\begin{tabular}{|c|c|c|c|c|c|c|c|c|c|}
\hline & \multicolumn{3}{|c|}{ Respiratory bronchiole } & \multicolumn{3}{|c|}{ Alveolar duct } & \multicolumn{3}{|c|}{ Alveolar wall } \\
\hline & $\begin{array}{c}\text { Degree of } \\
\text { muscularization }\end{array}$ & $\begin{array}{l}\text { No. of } \\
\text { arteries }\end{array}$ & $\begin{array}{c}\text { Percent } \\
\text { distribution }\end{array}$ & $\begin{array}{c}\text { Degree of } \\
\text { muscularization }\end{array}$ & $\begin{array}{l}\text { No. of } \\
\text { arteries }\end{array}$ & $\begin{array}{c}\text { Percent } \\
\text { distribution }\end{array}$ & $\begin{array}{c}\text { Degree of } \\
\text { muscularization }\end{array}$ & $\begin{array}{l}\text { No. of } \\
\text { arteries }\end{array}$ & $\begin{array}{c}\text { Percent } \\
\text { distribution }\end{array}$ \\
\hline \multirow{3}{*}{$N^{\omega}$-nitro-L-arginine infusions $(n=5)$} & Fully & 18 & 32.1 & Fully & 2 & 1 & Fully & 0 & 0 \\
\hline & Partially & 16 & 27.8 & Partially & 4.6 & 2 & Partially & 2 & 0.5 \\
\hline & Absent & 22 & 40.1 & Absent & 49 & 93.4 & Absent & 42 & 99.5 \\
\hline \multirow{3}{*}{ Saline infusions $(n=4)$} & Fully & 17 & 39.3 & Fully & 1 & 3.5 & Fully & 1 & 0.8 \\
\hline & Partially & 9 & 20.9 & Partially & 2 & 5.2 & Partially & 0 & 0 \\
\hline & Absent & 18 & 39.8 & Absent & 39 & 91.3 & Absent & 63 & 99.2 \\
\hline
\end{tabular}

inhibition did not alter pulmonary vascular smooth muscle morphology. This suggests that endogenous NO alone is not a critical modulator of pulmonary vascular smooth muscle proliferation in late-gestation fetal sheep. However, this study was not designed to address this question and does not rule out a role for endogenous $\mathrm{NO}$ in modulating pulmonary vascular smooth muscle proliferation. Further studies, including longer periods of NO inhibition, are needed.

In previous studies, acute NO inhibition did not reproduce persistent pulmonary hypertension (15). We also performed several preliminary investigations which showed that $N^{\omega}$-nitro$\mathrm{L}$-arginine infusions of $<7 \mathrm{~d}$ in duration did not reproduce persistent pulmonary hypertension. Therefore, the chronic $N^{\omega}$ nitro-L-arginine infusions utilized in this study most likely produce a more complete inhibition of NO synthesis, which is responsible for the persistent pulmonary hypertension.

Previous studies have shown that $N^{\omega}$-nitro-L-arginine induces NO inhibition by competitively inhibiting the oxidation of $\mathrm{L}$-arginine to $\mathrm{L}$-citrulline, and that excess $\mathrm{L}$-arginine administration can overcome this inhibition $(14,27) .3 \mathrm{~h}$ after delivery, an intravenous infusion of $\mathrm{L}$-arginine completely reversed the physiologic derangements in our model. This finding, in a setting of normal pulmonary vascular morphology, strongly suggests that the physiologic derangements were produced purely by nitric oxide inhibition, and are reversible with initiation of NO production. Because NO inhibition was produced by $N^{\omega}$ nitro-L-arginine in this model, L-arginine will overcome the competitive inhibition and restore NO production. However, this does not imply that L-arginine will improve the physiologic derangements of infants with PPHN. For example, if vascular injury results in inability to produce or respond to NO, L-arginine administration will have no effect.

In summary, we found that chronic NO inhibition induced by the continuous infusion of $N^{\omega}$-nitro-L-arginine in utero reproduced the physiologic derangements of persistent pulmonary hypertension after birth. Over the 3-h study period after birth, these lambs had persistent elevation of pulmonary arterial pressure which often exceeded systemic arterial pressure, elevated pulmonary vascular resistance, and decreased pulmonary blood flow. These derangements were obtained without pulmonary vascular remodeling and were completely reversed after reversal of NO inhibition with administration of L-arginine. This study establishes the important role of NO activity during the transitional circulation from fetal to newborn life, and provides a link between NO inhibition and the pathophysiology of PPHN. We speculate that in utero events resulting in endothelial dysfunction and NO inhibition may produce the physiologic derangements of PPHN.

\section{Acknowledgments}

The authors thank Roger Chang for expert technical assistance and Randy Kikukawa for editorial assistance.

This research was supported by grants HL 35518 and HL 41387 from the National Heart, Lung and Blood Institute and by the University of California San Francisco Academic Committee on Research.

\section{References}

1. Rudolph, A. M. 1979. Fetal and neonatal pulmonary circulation. Annu. Rev. Physiol. 41:383-395.

2. Cassin, S., G. S. Dawes, J. C. Mott, B. B. Ross, and L. B. Strang. 1964. The vascular resistance of the foetal and newly ventilated lung of the lamb. J. Physiol. (Lond.). 171:61-79.

3. Teitel, D. F., H. S. Iwamoto, and A. M. Rudolph. 1991. Changes in the pulmonary circulation during birth-related events. Pediatr. Res. 30:62-68.

4. Heymann, M. A., A. M. Rudolph, A. S. Neils, and K. L. Melmon. 1969. Bradykinin production associated with oxygenation of the fetal lamb. Circ. Res. 25:521-534.

5. Leffler, C. W., T. L. Tyler, and S. Cassin. 1978. Effect of indomethacin on pulmonary vascular response to ventilation of fetal goats. Am. J. Physiol. 234:H346-H351.

6. Leffler, C. W., J. R. Hessler, and R. S. Green. 1984. Mechanism of stimulation of pulmonary prostacyclin synthesis at birth. Prostaglandins. 28:877-887.

7. Haworth, S. G. 1988. Pulmonary vascular remodeling in neonatal pulmonary hypertension: state of the art. Chest. 93:133S-138S.

8. Levin, D. L., M. A. Heymann, J. A. Kitterman, G. A. Gregory, R. H. Phibbs, and A. M. Rudolph. 1976. Persistent pulmonary hypertension of the newborn. J. Pediatr. 89:626-630.

9. Soifer, S. J., and M. A. Heymann. 1993. Persistent pulmonary hypertension of the newborn. In Fetus and Neonate: Physiology and Clinical Applications. Vol. 1: The Circulation. M. A. Hanson, J. A. D. Spencer, and C. H. Rodeck, editors. Cambridge University Press, Cambridge, UK. 225-251.

10. Roberts, J. D., D. M. Polaner, P. Lang, and W. M. Zapol. 1992. Inhaled nitric oxide in persistent pulmonary hypertension of the newborn. Lancet. 340:818-819.

11. Kinsella, J. P., S. R. Neish, E. Shaffer, and S. H. Abman. 1992. Low-dose inhalational nitric oxide in persistent pulmonary hypertension of the newborn. Lancet. 340:819-820.

12. Ignarro, L. J. 1989. Biological actions and properties of endothelium-derived nitric oxide formed and released from artery and vein. Circ. Res. 65:1-21.

13. Palmer, R. M. J., D. S. Ashton, and S. Moncada. 1988. Vascular endothelial cells synthesize nitric oxide from L-arginine. Nature. 333:664-666.

14. Fineman, J. R., M. A. Heymann, and S. J. Soifer. 1991. $N^{\omega}$-nitro-l-arginine attenuates endothelium-dependent pulmonary vasodilation in lambs. $\mathrm{Am}$. J. Physiol. 260:H1299-H1306.

15. Abman, S. H., B. A. Chatfield, S. L. Hall, and I. F. McMurtry. 1990. Role of endothelium-derived relaxing factor during transition of pulmonary circulation at birth. Am. J. Physiol. 259:H1921-H1927.

16. Moore, P., H. Velvis, J. R. Fineman, S. J. Soifer, and M. A. Heymann. 1992. EDRF inhibition attenuates the increase in pulmonary blood flow due to oxygen ventilation in fetal lambs. J. Appl. Physiol. 73:2151-2157. 
17. Fiscus, R. R. 1988. Molecular mechanisms of endothelium-mediated vasodilation. Semin. Thromb. Hemostasis. 14:12-22.

18. Radomski, M. W., R. M. J. Palmer, and S. Moncada. 1987. Endogenous nitric oxide inhibits human platelet adhesion to vascular endothelium. Lancet. 2:1057-1058.

19. Garg, U. C., and A. Hassid. 1989. Nitric-oxide-generating vasodilators and 8-bromo-cyclic guanosine monophosphate inhibit mitogenesis and proliferation of cultured rat smooth muscle cells. J. Clin. Invest. 83:1774-1777.

20. Tiktinsky, M. H., and F. C. Morin III. 1993. Increasing oxygen tension dilates fetal pulmonary circulation via endothelium-derived relaxing factor. $\mathrm{Am}$. J. Physiol. 265:H376-H380.

21. Haworth, S. G., and L. M. Reid. 1976. Persistent fetal circulation: newly recognized structural features. J. Pediatr. 88:614-620.

22. Murphy, J. D., M. Rabinovitch, J. D. Goldstein, and L. M. Reid. 1981. The structural basis of persistent pulmonary hypertension of the newborn infant. J. Pediatr. 98:962-967.

23. Levin, D. L., L. J. Mills, and A. G. Weinberg. 1979. Hemodynamic, pulmonary vascular, and myocardial abnormalities secondary to pharmacologic constriction of the fetal ductus arteriosus. A possible mechanism for persistent pulmonary hypertension and transient tricuspid insufficiency in the newborn infant. Circulation. 60:360-364.

24. Abman, S. H., P. F. Shanley, and F. J. Accurso. 1989. Failure of postnatal adaptation of the pulmonary circulation after chronic intrauterine pulmonary hypertension in fetal lambs. J. Clin. Invest. 83:1849-1858.

25. Morin, F. C. 1989. Ligating the ductus arteriosus before birth causes persistent pulmonary hypertension in the newborn lamb. Pediatr. Res. 25:245250.

26. Wild, L. M., P. A. Nickerson, and F. C. Morin. 1989. Ligating the ductus arteriosus before birth remodels the pulmonary vasculature of the lamb. Pediatr. Res. 25:251-257.
27. Ishii, K., B. Chang, J. F. Kerwin, Jr., Z. Huang, and F. Murad. 1990. $N^{\omega}$-nitro-L-arginine: a potent inhibitor of endothelium-derived relaxing factor formation. Eur. J. Pharmacol. 176:219-223.

28. Reid, L. M. 1979. The pulmonary circulation: remodeling in growth and disease. Am. Rev. Respir. Dis. 119:531-546.

29. Barcroft, J. 1946. Researches on Pre-natal Life. Blackwell Scientific Publications, Oxford, UK. 43 pp.

30. Moncada, S., D. D. Rees, R. Schulz, and R. M. J. Palmer. 1991. Development and mechanism of a specific supersensitivity to nitrovasodilators after inhibition of vascular nitric oxide synthesis in vivo. Proc. Natl. Acad. Sci. USA. 88:2166-2170.

31. McMahon, T. J., J. S. Hood, J. A. Bellan, and P. J. Kadowitz. 1991. $N^{\omega}$-nitro-l-arginine methyl ester selectively inhibits pulmonary vasodilator responses to acetylcholine and bradykinin. J. Appl. Physiol. 71:2026-2031.

32. Rubanyi, G. M., J. C. Romero, and P. M. Vanhoutte. 1986. Flow-induced release of endothelium-derived relaxing factor. Am. J. Physiol. 250: H1145H1149.

33. Buga, G. M., M. E. Gold, J. M. Fukuto, and L. J. Ignarro. 1991. Shear stress-induced release of nitric oxide from endothelial cells grown on beads. $H y$ pertension (Dallas). 17:187-193.

34. Cornfield, D. N., B. A. Chatfield, J. A. McQueston, I. F. McMurtry, and S. H. Abman. 1992. Effects of birth-related stimuli on 1-arginine-dependent pulmonary vasodilation in ovine fetus. Am. J. Physiol. 31:H1474-H1481.

35. Davidson, D. 1988. Pulmonary hemodynamics at birth: effects of acute cyclooxygenase inhibition in lambs. J. Appl. Physiol. 64:1676-1682.

36. Murphy, J. D., M. J. Aronovitz, and L. M. Reid. 1986. Effects of chronic in utero hypoxia on the pulmonary vasculature of the newborn guinea pig. $\mathrm{Pe}$ diatr. Res. 20:292-295.

37. Geggel, R. L., M. J. Aronovitz, and L. M. Reid. 1986. Effects of chronic in utero hypoxemia on rat neonatal pulmonary arterial structure. J. Pediatr. 108:756-759. 